\title{
Behavioral Research on Captive Animals: Scientific and Ethical Concerns
}

\author{
Kimberley Jayne \\ Senior Science Researcher, Animal Defenders International, Lord Dowding \\ Fund for Humane Research, London, United Kingdom. Collective Member, \\ European Association for Critical Animal Studies \\ kimberley.jayne@outlook.com
}

\begin{abstract}
Adam See
PhD Candidate, The Graduate Center, City University of New York, New York, United States
\end{abstract}

\section{Modeling Wild Animal Behavior in the Laboratory: Scientific Concerns}

- KimberleyJayne -

Behavioral research on non-human animals (hereinafter referred to as animals) can involve the study of their evolution and natural behavior, cognitive abilities and psychological constructs, or welfare and response to stressors, among other areas of natural animal behavior. Behavioral research on animals is also carried out to model human behavior, for example in psychological studies and pharmacological models, as well as for comparative purposes to understand differences and similarities between species. This chapter focuses on the former - where ethology moves into the laboratory environment to model the behavior of free living animals - however, some of the discussion is also relevant to the laboratory animal model in general because of the very nature of using laboratory animals as "models". For further discussion on animals used to model disease or within pharmacology in particular, see the following chapters in this Volume: Archibald, Coleman and Drake (2019, Chapter 18); Bailey (2019, Chapter 19); Carvalho et al., (2019, Chapter 16); Greek and Kramer (2019, Chapter 17); Pippin, Cavanaugh and Pistollato (2019, Chapter 2o); and Ram (2019, Chapter 15). For more on animal models within psychology, see Shapiro (1998).

In comparison to other scientific procedures, such as those within biomedical research, modeling the behavior of wild animals in the laboratory can involve

(C) KIMBERLEY JAYNE AND ADAM SEE, 2019 | DOI:10.1163/9789004391192_022 
methods that are physically non-invasive. While it is true that some behavioral studies are accompanied by invasive measures (which can be anything from injecting dye for identification purposes, to drilling into the skull to insert brain implants), for those that are not, physical and psychological suffering may be overlooked. This can also affect the rigor with which the 3 Rs are applied, with the implementation of replacement in behavioral research being of particular concern. Nevertheless, the welfare of animals used for behavioral research can suffer as a direct result of: experimental manipulations (e.g., simulating prolonged presence of predators); marking methods (Association for the Study of Animal Behaviour, 2018); from being wild-trapped and transported to a laboratory; or simply living in a laboratory environment can result in various degrees of suffering by impeding an animal from performing natural behavior, imposing a chronic state of fear, or observing them at close proximity (particularly if they are a prey or territorial species). Moreover, research in the name of animal welfare brings about scientific concerns with studying wild animal behavior in the laboratory, as well as problems with the animal model in general.

The first half of this chapter focuses exclusively on animals that are used in laboratory behavioral research to model wild behavior, what is typically involved, problems associated with this practice, and how behavioral research has revealed scientific problems in the animal model. The second half of this chapter then addresses the ethical questions of whether scientific curiosity of animal behavior in general provides any justification for carrying out this research in this first place, with specific focus on non-human primates (NHPs).

\subsection{The Origins of Laboratory Behavioral Research}

The study of animal behavior has a long history, dating back over 2000 years; however laboratory behavioral research became popular in the twentieth century with the rise of behaviorism, with research using animal models to understand more about the human processes of learning and memory and the comparative abilities of animals (Klopfer, 1993). Food deprivation was frequently used as a method to motivate laboratory animals to "perform" and is still frequently used today across behavioral research. For example, early studies by Thorndike in 1898 deprived cats of food and confined them in a "puzzle box", from which they had to work out how to escape for a food reward (Chance, 1999). In the 1920s, Pavlov used dogs to demonstrate the principals of classical conditioning: a dog was restrained and isolated in a room for use in a series of trials where food was presented with a neutral event (e.g., flashing of a light), so that their salivation response could be recorded (Pavlov, 1927). Still used today (e.g., Meier, Lea and McLaren, 2016), and developed in the 1920s by Skinner, the Skinner Box (sometimes referred to as an "operant chamber") confines partially food-deprived animals (often pigeons or rats) inside of a box 
with a device they must operate to obtain a food reward. Sometimes animals were also given amphetamines to assess the impact on their behavior under these conditions (Dews, 1955). Laboratory research has also used animals to model other aspects of human behavior: Seligman and colleagues gave dogs electric shocks they could not escape to model learned helplessness associated with human depression (Abramson, Seligman and Teasdale, 1978); Harlow (1958) isolated infant rhesus macaques from their mothers to raise them in complete social isolation, or with a "cloth mother" or "wire mother" surrogate. Despite studies with humans being carried out, which reveal human-relevant data, six decades later this type of research continues with infant monkeys (e.g., Massart et al., 2014). So has the use of animal models of learned helplessness, which have been going on for five decades, particularly with rodents (e.g., Greenwood, Strong and Fleshner, 2010; for review see Maier and Seligman, 2016).

Alongside the rise in laboratory behavioral research, a contrasting method of studying the natural behavior of animals, known as ethology, gained popularity during the mid-twentieth century through the work of Lorenz, Tinbergen and von Frisch (Bolhuis and Geraldaue, 2008; Klopfer, 1993). The purpose of ethology was to ask questions about animals in their natural environment, using non-intrusive observational methods or environmental manipulations (Klopfer, 1993). However, for the opportunity to study them close up and/or under controlled conditions, ethologists have frequently brought animals into the laboratory—now common practice in modern behavioral research — and used invasive techniques with free-living, wild animals. For example, early ethological studies used chronically implanted electrodes to stimulate areas of the brain (Klopfer, 1993); and homing pigeons were fitted with contact lenses (Schmidt-Koenig and Schlichte, 1972) and, more recently, had their olfactory nerve cut to study the impact upon their ability to navigate (Gagliardo et al., 2008).

\section{2}

\section{Ethology in the Laboratory}

In modern ethology research, animals are studied in the wild and in captivity. Animals that are used in laboratories are either captive bred or caught from the wild in order to study behavior seen in their wild counterparts, but in an environment where they are in closer visual proximity and where their behavior can be observed and manipulated under controlled conditions. The number of animals involved in behavioral research worldwide is unknown because many are not documented and, in the UK, only research that is considered to cause an animal "pain, suffering, distress, or lasting harm" (U K Home Office, 2012) is subject to licensing and therefore reported. However, potentially, a large number of undocumented behavior studies could be carried out that could still 
cause an animal a degree of distress, even if the distress is simply a result of the captive environment or being observed. And even more animals may simply be housed in laboratories but not the subject of current procedures (e.g., University College London, 2017). While some countries do not report behavioral research in their statistics, the most recent United Kingdom statistics show that out of 3,936,723 procedures, involving the use of live animals, 55,475 come under the category of behavioral research that causes, "pain, suffering, distress, or lasting harm" (accounting for approximately $1.4 \%$ of procedures) (UK Home Office, 2017a). This includes research on mice, rats, other rodents, carnivores, pigs, sheep, birds, amphibians, and fish.

Laboratory studies of wild animal behavior cover a wide range of research questions, including questions about their evolution and adaptations, development, cognitive abilities, social behavior, and even how their behavior is affected by captivity, among many other areas. For example, fish are used in large numbers in laboratories ( $78 \%$ of behavioral research in the UK) (UK Home Office, 2017a); and even more fish are bred to maintain genetic lines (e.g., Greenwood et al., 2013), with some taken from the wild to test under laboratory conditions (e.g., Burns et al., 2016). Research can involve exposing animals to aversive stimuli, such as simulating predator presence to observe their anti-predator behavior (e.g., Brilot and Bateson, 2012); manipulating different social conditions, for example, to monitor how males harass females (Killen et al., 2015); and assessing whether specific behaviors are indicative of pain or suffering (Braithwaite and Boulcott, 2007). Both N HPs and birds are frequently used for comparative cognition studies to study how abilities that are characteristically human may have adaptive qualities for animals. For example, to study concepts, such as numerosity, theory of mind, language, economic decision making, tool use, and memory (Call and Tomasello, 2008; Clayton and Emery, 2005; Pepperberg, 2017). In laboratory studies of this nature, an animal will typically be within a confined space and given a problem to solve, for example, using an apparatus or on a computer screen, for which they would receive food as a reward (e.g., Meier, Lea and McLaren, 2016). Some cognition research also involves invasive procedures, such as fixing recording chambers to an animal's skull (e.g., Schechtman et al., 2016); or being restrained in stereotactic frames (e.g., Neubert et al., 2015), to take brain recordings alongside behavioral measures.

\subsection{Laboratory Animal Welfare Research}

Animals who live in laboratories are affected by their environment in ways that makes their behavior different from free-living animals. These behavioral changes can be negative for the animal, as well as for the scientific output. For this reason, there is a separate field of behavioral research that studies the 
welfare of laboratory housed animals, where animals are observed and experimented upon to ascertain how they deviate from their wild counterparts, as a result of the conditions of their captive environment. Therefore, not only do animals suffer as a direct result of experimental procedures but, because the stress and deprivation of a laboratory environment is known to cause welfare concerns, additional animals are housed and experimented upon in order to examine the effects that a laboratory can have upon behavior, welfare, and, ultimately, scientific results.

For animals who live within captive environments the ecological pressures are significantly different from the environment in which their wild counterparts have evolved. Their surroundings are smaller, uncontrollable, and less complex than their natural habitat. They engage in social interaction that is distinct from what they would naturally experience (e.g., in terms of group size, proximity, sex ratio, or hierarchy). Furthermore, they are prevented from performing many of their natural behaviors, such as in preparation for feeding, but are exposed to unnatural routines imposed by their carers (Bassett and Buchanan-Smith, 2007), including: being caught and handled (Gouveia and Hurst, 2017; Hosey, 2005); unfamiliar sounds (including ultrasonic noise from computers); lighting and temperature (Gaskill, 2016; Reardon, 2016); and even cage cleaning, which has been found to disrupt olfactory communication and increase aggressive behavior (Arakawa et al., 2008). The presence of abnormal behaviors is common in captive animals and is considered a direct result of living in these environments. These behaviors can develop as a result of unavoidable stress or fear, as a frustrated response to being prevented from performing a behavior, or through lack of stimulation. The presence of abnormal behavior is considered a significant indicator of reduced welfare. These behaviors can include repetitive locomotor stereotypies, such as somersaulting, pacing or body-rocking, bar-mouthing, and self-injurious behavior (reviewed in Mason and Rushen, 2006). Laboratory animals can even experience "contagious anxiety" physiological changes that occur as a result of observing conspecifics undergoing procedures (Gewin, 2011; Lutz et al., 2016; Novak et al., 2013). The presence of such behavior is absent in free-living animals, making the justification for studying wild-like behavior in laboratory animals questionable, and problematic when animals are used to model human behavior (for further discussion of how laboratory animal behavior and welfare impacts on modeling the human condition, see Herrmann, 2019, Chapter 1 in this Volume).

Nevertheless, to understand more about abnormal behaviors prevalent in existing laboratory animals, experiments are carried out on more animals to investigate factors that influence the occurrence of these behaviors and ways to reduce or eliminate them in laboratory-confined animals. For example, to determine whether wild-caught animals might be more susceptible to 
laboratory stressors, infant animals are taken from the wild to compare their behavioral responses with those that have been hand-reared in the laboratory (Jayne, Feenders and Bateson, 2013); to assess the effects of different enrichments, some animals are forced to live in barren cages (Abou-Ismail and Mahboub, 2011); and to examine the effect of different social conditions, animals are exposed to various stressors, such as predator cues, to measure their stress response (Zoratto et al., 2014).

Welfare research has shown that even small differences across laboratory environments can have varying effects upon stress and the expression of abnormal behavior and development. For example, monkeys that are separated from their mothers and raised by their peers display abnormal behaviors later in life, as well as long lasting effects on their stress hormones, compared to those who do not experience early maternal separation (Feng et al., 2011). Differences in housing and husbandry, such as introducing an artificial burrow, can impact the expression of abnormal behavior (Waiblinger and Koenig, 2007). Having visual access to conspecifics has even been shown to affect stress levels and cognitive performance (Harris, D'Eath and Healy, 2010).

Research has shown that stress of the laboratory environment is not only associated with abnormal behavioral development, but also has long-term effects on abnormal physiological development and even brain functioning, with abnormal behaviors actually thought to reflect permanent brain dysfunction (Knight, 2001). For example, the basal ganglia, responsible for motor control, show altered responding in rodents and birds displaying abnormal behavior (Garner and Mason, 2002; Garner, Mason and Smith, 2003); sensory and motor deprivation are thought to be associated with impaired brain development (van Praag, Kempermann and Gage, 200o); and abnormal repetitive behaviors are considered to originate from chronically thwarted attempts to perform specific behaviors or to gain access to resources (Würbel, 2001). Psychological stress can also affect the body in other physiological ways. For example, sporadic noise stress administered to rats can encourage the display of abnormal rearing behavior, as well as impact their gut morphology (Baldwin, Primeau and Johnson, 2006) and the functioning of their autonomic nervous system (Burwell and Baldwin, 2006), among other stress-related diseases (Gaskill, 2016). In addition, being prevented from performing one's natural behavior can result in reduced physiological condition (Makowska and Weary, 2016). Overall, animals living in the laboratory are vulnerable to abnormal behavior, physiology, and brain development. They do not represent "healthy" models of free-living individuals of their species, thereby questioning the validity of research using these animals to model natural animal behavior within the laboratory (Würbel, 2007). (Note that there are areas of research that indeed require 
animal models to display conditions not present in healthy wild populations, such as in disease research, but critique of these models is beyond the scope of this chapter.)

\subsection{The Validity, Reliability, and Replicability of Modeling Wild Animal Behavior in the Laboratory}

For research where "abnormal models" are undesirable, as is the case for modeling wild behavior, the presence of abnormal behaviors has been identified as a scientific problem that can compromise a study's validity, reliability, and replicability; thereby questioning the wider knowledge that can be gained from such models. Experimental validity measures the degree to which a test measures what it is supposed to test, including whether the effects were indeed caused by the treatment (internal validity); and whether the sample used is representative of a target population (external validity). When ethological studies are brought into the laboratory, threats to both internal and external validity are particularly problematic when using abnormally behaving animals to model "normal" behavior (Würbel, 2001, 2007). Reliability in an experiment means that the same result would be obtained from repeated observations or from multiple measurement devices. The likelihood that the outcome is reliable is reduced by using animals that show abnormal behaviors in experiments. This increases the amount of interindividual variation in an experiment (Garner, 2005), particularly if that variation affects the natural behavior being modeled. The replicability of an experiment refers to the extent to which the results can be repeated, for example, across different laboratories, which is affected by the variability in abnormal behaviors from atypical models seen between different laboratories (Garner, 2005). Garner (2005) describes how the brain mechanism that produces abnormal behavior "can and does" affect experimental outcomes in behavioral studies that measure response latencies, cage activity, behavioral switching, and extinction learning; he shows that different types of housing and laboratory environments can affect the prevalence of these behaviors and, therefore, the validity, reliability, and replicability of a behavioral experiment (p. 112). What is even more concerning from a scientific point of view is the prevalence of abnormal behaviors in laboratory animals; for example, it is estimated that $50 \%$ of laboratory mice display abnormal behaviors, which they start to develop right after weaning at 21 days old (Würbel and Stauffacher, 1994; Würbel, Stauffacher and von Holst). Therefore, a potentially large number of animals are being used, which are unsuitable for modeling behavior of the same species living in their natural environments, and providing results that are invalid, unreliable, and unreplicable. 


\subsection{Other Scientific Concerns}

Some experiments, such as those within animal cognition (e.g., exploring innovative problem solving), over-rely on using a small number of individuals, typically raised in unnatural, barren or restrictive environments, as an exemplar of their species' cognitive capacities (Allen, 2002; Boesch, 2007, 2008; Leavens, Bard and Hopkins, 2010). This is particularly true for research using great apes. These experiments can involve the repetitive use of a small number of the same individuals, animals that have been exposed to countless numbers of trials with different variations of problems they must solve. While measures are taken to try to control for the effect of learning or environment, it is not possible to eliminate these variables as reasons for the findings in these studies; and, hence, they could explain individual differences apparent in studies using animals who have been used many times in previous research (e.g., Tecwyn, 2013; Tecwyn, Thorpe and Chappell, 2012). In particular, there is debate regarding the epistemic legitimacy of drawing species-level generalizations from studies that use captive primates. For example, Tomasello and Call (2008) controversially assert that the cognitive capacities of captive chimpanzees are not affected negatively by their unnatural environment. To the contrary, they note that captive chimpanzees have repeatedly demonstrated a range of impressive abilities not observed in their wild counterparts. In response, Boesch $(2007,2008)$ argues that the cognitive potential of enculturated chimpanzees is beside the point; the issue lies in making fair cross species comparisons. Boesch (2007) states: "The recent acceptance of experimental studies, with captive individuals considered as fully representative of an entire species, is based on the assumption that socioecological factors play a minimal role in the development of the cognitive and cultural abilities of the individual" (p. 3). Despite legitimate concerns of this nature, the results of experiments on captive populations are often considered-whether tacitly (e.g., Povinelli et al., 2000; Silk et al., 2005) or explicitly (e.g., Tomasello and Call, 1997, 2008)to be indicative of the cognitive capacities (or lack thereof) of conspecifics across all developmental contexts. Indeed, extensive evidence already exists that different environmental experiences affect not only the cognitive development of NHPs, and other non-human animals (see Nelson, de Haan and Thomas, 2006, for a review), but that of humans as well. For example, human infants raised in different environments perform differently on tests designed to evaluate capacities for spatial reasoning, theory of mind, and numerical ability (see Boesch, 2008, for a review). Furthermore, Boesch (2007) points out that the acceptance of captive studies as representative of species' abilities can strongly discourage more ecologically relevant cognitive studies with wild populations. 
A laboratory environment can never adequately simulate the natural life of a wild animal in an ecologically realistic way and with the same ecological pressures; frequently, the experiments they are exposed to, even for ethology laboratory research, do not represent real problems for which they have evolved to solve (Jayne, 2014). While controlling variables under laboratory conditions allows their effects to be studied in isolation from one another, as well as enabling behavior to be studied close up, these measures do not realistically represent how they would appear in wild populations (Leavens, Bard, and Hopkins, 2010), and thus affect the external validity or ecological relevance of a study (Bailoo, Reichlin and Würbel, 2014). For this reason, some experiments that are carried out to model wild behavior cannot always be replicated under controlled laboratory conditions (Jayne, 2014). For example, Boesch and Boesch-Achermann (2000) argue precisely this in relation to theory of mind research carried out in captive chimpanzees:

No captive study has so far attempted to study the chimpanzee's theory of mind, but all have confronted the chimpanzees with totally new situations to pass tests to show the human's theory of mind. This may address the question of [the] chimpanzee[s'] potential, but does not answer questions about the theory of mind that chimpanzees use in their daily lives. If some of these tests did not demonstrate a theory of mind in captive chimpanzees, we should not be surprised but rather ask ourselves "What kind of theory of mind is adaptive for chimpanzees to acquire?" and "When do they use it?". (p. 243)

\subsection{The Utility of Ethological Research in the Laboratory}

In relation to the scientific concerns of modeling wild animal behavior in the laboratory, a further problem is the extent to which the findings are even desirable in advancing our knowledge of behavior in wild-living individuals, given the methods used to obtain them. This is of particular relevance for determining whether the gains of the research, in terms of human knowledge about a species and their behavior, outweigh the harms to the animal, which appears to be played down when planning a laboratory study of wild animal behavior (personal analysis of UK non-technical summaries; UK Home Office, 2017b), although it should be a vital part of all harm-benefit analyses.

Furthermore, while the ${ }_{3}$ Rs must be addressed for any laboratory animal study that takes place-at least under European Union (EU) regulations, among other systems - the urgency with which they are applied to this type of behavioral research is minimal, in comparison to other fields of animal 
research, particularly for replacement (personal analysis of EU funding dedicated to the ${ }_{3}$ Rs for laboratory behavioral/ethology research, 2017). Any legal requirement to seek non-animal replacements is easily disregarded in behavioral research because animals are the target species (Cuthill, 2007). Some non-animal methods are available for behavioral research and have been around for decades, such as computer modeling for analyzing shoaling and flocking behavior (Huston, 1988; Mwaffo, Butail and Porfiri, 2017); or computer programs with virtual animals that can be used for educational purposes (Graham, Alloway and Krames, 1994; Behavior on a Disk, n.d.); however, these may not be suitable replacements for many types of behavioral study. Thus, because the behavioral studies discussed here are specifically designed to model wild behavior, in close proximity and under controlled conditions not always possible in an animal's natural environment, the requirement for replacement is undermined and, as a consequence, the scientific concerns are given minimal weight.

Although studying the behavior of wild animals in the laboratory is a small field of research, relative to other areas where animals are modeled, phasing out the use of animals for this nature of research is particularly favorable: first, because of the scientific reasons already outlined; and second, because there is an obvious replacement available for researchers to ask the same questions (or at the very least, similar and refined questions) about behavior, namely, observing the natural behavior of wild and free-living animals. And where the study of free-living animals is not feasible, researchers need to consider whether the scientific knowledge gained from using laboratory models is even desirable. In terms of harm-benefit assessment, more critical scrutiny by researchers and licensing bodies should find that the harms do not outweigh the gains to scientific knowledge from attempting to model wild behavior in the laboratory, not least the ethical concerns (which are addressed in the second part of this chapter). This is a field of research where it is practicable to end animal use under these conditions and could be applied with minimal negative outcomes for researchers, who should still be able to continue their study under more scientifically favorable conditions, namely, with wild, free-living animals.

\subsection{Concluding Remarks}

Due to the smaller numbers of animals used, and with typically less invasive procedures, ethology laboratory studies often receive little attention when the ${ }_{3}$ Rs are discussed. The necessity of the research, however, is a different matter; for example, in cognition research, efforts to test whether animals are "intelligent" focus on their abilities to show human-like capabilities, which is 
irrelevant to their evolutionary history or ecological needs (see Bekoff, 2013a, $2013 \mathrm{~b}$; and the second part of this chapter, for further discussion).

The Association for the Study of Animal Behaviour (ASAB) states that: "[i]f procedures used in research or teaching involve animals' exposure to painful, stressful or noxious stimuli, whether through acts of commission or omission, the investigator must consider whether the knowledge that may be gained is justified" (2018, p. III). Ultimately, laboratory behavioral research shows us that the stress animals experience as a result of living in a laboratory impacts the outcomes of experiments in such a way that the information gained from these experiments may not be reliable or valid and, therefore, not justified. ASAB (2018, p. I) also state that "Behavioural studies are of great importance in increasing our understanding and appreciation of nonhuman animals". Behavioral welfare studies reveal that laboratory animals are a poor scientific model for increasing our understanding of animal behavior and welfare and, particularly, for modeling behavior seen in wild animals (Garner, 2005; Würbel, 2007). In terms of furthering our knowledge and understanding of other animals, there are far more non-intrusive methods, such as ethological field studies where an animal's natural behavior can be appreciated for its own worth, rather than using animals for hypothetical human gains. The study of the natural behavior of animals is fascinating, and none more so than when they are free to express their full behavioral repertoire in their own habitat. Furthering our understanding of animal behavior is entirely possible using non-intrusive approaches whilst still being grounded in the scientific method, such as through direct observations, or even experimentally by incorporating environmental manipulations (e.g., Jayne, Lea and Leaver, 2015; Klopfer, 1993).

Although laboratory behavioral research may rarely come under the category of causing "severe" suffering (unless being carried out alongside invasive procedures), for ethology studies; we have seen, from the first part of this chapter, that some experimental methods cause animals to experience psychological stress to such a degree that it can affect their long-term physiological development. Even simply living in a laboratory environment can result in a sufficient amount of stress to bring about permanent changes in behavior, physiology, and brain development (e.g., Makowska and Weary, 2016; van Praag, Kempermann and Gage, 2000; Würbel, 2001). Ultimately, a laboratory can never adequately provide an environment for an animal to behave in an ecologically relevant way for experimental findings to inform about natural behavior or evolved abilities. Accordingly, the continued use of laboratory animals for ethology research is not scientifically desirable or necessary, as well as being fraught with ethical problems, as the second part of this chapter illustrates. 
The remainder of this chapter focuses on underrepresented ethical issues arising from behavioral research in comparative cognition or, more generally, the study of animal minds. As the range of potential topics of interest here is immense, discussion is limited to the following: 1. behavioral research conducted in captive environments, i.e., zoos and research centers; 2. controlled studies on non-human primates (N HPs); and 3. research motivated solely by scientific curiosity, i.e., pure or basic research as opposed to applied research, such as theory of mind debates. Research in this vein has, to our knowledge, never been subject to sustained ethical scrutiny. The primary aim of what follows is to motivate this conversation.

\subsection{Behavioral Research on Non-human Primates}

Great ape and monkey species have long been staples of both behavioral and biomedical research in the United States (Us) and in the European Union. Biomedical research on great apes has been (mostly) banned in the EU (European Parliament, 2010, Directive 2010/63/EU, Article 8; though see various safeguard clauses in Article 55); and in the Us, where the Fish and Wildlife Services recently granted chimpanzees endangered species status (2015; more on this law below). However, so-called "non-invasive" or "behavioral" research on great apes, and especially other NHPs, continues largely untouched in these countries.

In the Us, the Ape Cognition and Conservation Initiative in Des Moines, Iowa, continues to house, breed, and conduct behavioral studies on bonobos, many of which focus on multi-modal communication (e.g., Taglialatela et al., 2015). The Yale Comparative Cognition Laboratory in New Haven, Connecticut, conducts behavioral research on the origins of human cognitive abilities in a "naturalistic" indoor enclosure, "equipped with natural branches and other toys" (Leimgruber, Rosati, and Santos, 2016; see also Cohen and Santos, 2016; Rosati and Santos, 2016). Behavioral research on monkeys, involving functional magnetic resonance imaging ( $\mathrm{fMRI}$ ), is also being conducted at Rockefeller University in New York City (e.g., Sliwa and Freiwald, 2017). The Yerkes Research Center (Yerkes) houses and breeds NHPs at both Emory University and a second location in Lawrenceville, Georgia. Their current population of NHPS is approximately 3,400 , though it is unclear what percentage is used exclusively for behavioral research (Yerkes, n.d.). Much of the behavioral research at Yerkes takes place in "sound attenuating booths" with computer touch screens, as well as a "foraging room" where monkeys "explore and learn in a large area 
where food can be hidden and puzzles presented" (Laboratory of Comparative Primate Cognition, n.d.). Recent behavioral research at Yerkes involves monkeys (e.g., Brown, Templer, and Hampton, 2017; Hassett and Hampton 2017), orangutans (e.g., Diamond et al., 2016), and chimpanzees (e.g., Krachun et al., 2016). What is more, the Comparative Intelligence and Cognition Laboratory at the Language Research Center at Georgia State University conducts a wide range of comparative experiments on chimpanzees, capuchin monkeys, rhesus monkeys, and human infants and adults. Nearly a dozen such experiments were conducted in 2016, with comparable numbers in previous years, focusing on topics, such as numerical cognition, metacognition, strategic economic interactions, prospective memory and planning, self-control and delay of gratification, and perceptual and cognitive illusions (Comparative Intelligence and Cognition Laboratory, n.d.).

Behavioral research on theory of mind, cognitive bias, cooperation, and fairness, among other areas, is also regularly conducted at zoos, such as Zoo Atlanta, which houses the largest population of gorillas, orangutans, and drill monkeys in the us (Zoo Atlanta, n.d.); and the Lester E. Fisher Center for the Study and Conservation of Apes at the Lincoln Park Zoo, which publishes a wealth of studies on sociocognitive abilities in chimpanzees (e.g., Brosnan et al., 2015; Hopper et al., 2015). Finally, behavioral research on NHPs in the us is also performed at field stations, such as the National Institutes of Health $(\mathrm{NIH})$ Animal Center at the Laboratory of Comparative Ethology in Poolesville, Maryland (e.g., Dettmer et al., 2016b; Wooddell et al., 2017). This field station is a five acre "naturalistic" environment from which primates are temporarily removed for reasons, such as manipulating group dynamics (e.g., "rank changes and troop stability") in their absence (e.g., Wooddell et al., 2017). Some studies involve separation of infant macaques from their mothers (e.g., Ferrari et al., 2009) for up to five intervals during the first month of their lives, while others do not (e.g., Dettmer et al., 2016a).

In the $\mathrm{EU}$, the most prominent institution for behavioral research is the Wolfgang Köhler Primate Research Center (Pongoland) in Leipzig, Germany, which houses 41 great apes. Notable recent studies include, the false-belief experiments of Krupenye et al. (2016) and Kano et al. (2017), which are the first tests in over 40 years of research on this subject, to demonstrate that apes possess an understanding of reality-incongruent mental states in others. The capacity to attribute false beliefs has long been the litmus test for whether chimpanzees possess a theory of mind, making these studies particularly significant.

The above survey of contemporary behavioral research on NHPs is hardly exhaustive, but it gives the reader a sufficient idea of the types of research under discussion here. Behavioral research is not easy to define. It can range from 
"purely-observational" research in the field, to controlled experimental trials in captive environments involving touch screens, "non-invasive" neural imaging, and competitive and collaborative activities with humans and conspecifics. It mostly occurs in zoos, sanctuaries, and research centers (laboratories with "naturalistic" enclosures). A great advantage of the mode of argumentation that follows is that concrete definitions are unnecessary. Both the moral principle presented below as well as the challenge that results from this principle are intended to apply to behavioral research in all of its iterations. As will become clear, certain behavioral research may be readily justifiable in accordance with this principle, while other behavioral research will not, and a great many cases will remain up for debate.

\subsection{Scientific Curiosity and the Ethics of Behavioral Research}

In comparative cognition, the vast majority of behavioral research has been, and continues to be, conducted on NHPs bred and raised in captivity (Andrews, 2015, p. 164). As mentioned above, chimpanzees continue to be widely used in behavioral research. Yet, as Birkett and Newton-Fisher (2011, p. 6) state, there is an "urgent need to understand how the chimpanzee mind copes with captivity, an issue with both scientific and welfare implications that will impact potential discussions concerning whether such species should be kept in captivity at all". Indeed, we share the concerns of Boesch $(2007,2008,2015)$ and Leavens, Bard and Hopkins (2010) that there is a desperate need to grapple with serious epistemic and methodological issues that arise from making population-to-species generalizations, based entirely on the behavior of captive chimpanzees. However, the focus in this discussion is on an even less represented issue: the welfare implications of behavioral research on these individuals. While biomedical research on chimpanzees and other non-human primates is a widely contentious issue amongst philosophers, scientists, and the general public alike, behavioral research has rarely been subject to moral scrutiny. Nonetheless, Malone and Palmer (2014, p. 33) are quite right that "although 'purely observational' research in the field and the zoo is often regarded as inherently good and only minimally problematic, complex ethical issues accompany research in both these settings". The same can be said for more hands on behavioral experiments in "naturalistic" indoor and outdoor environments at primate research centers. Over the past few years, behavioral research on chimpanzees has, thankfully, been the subject of several excellent papers (Baker and Dettmer, 2016; Fedigan, 2010; Gruen, Fultz and Pruetz, 2013; Hosey, 2005, 2008; Mackinnon and Riley, 2010; Malone, Fuentes and White, 2010; Malone and Palmer, 2014). This discussion does not summarize the myriad of issues that they raise but rather concludes by highlighting a crucial challenge 
to behavioral studies on captive N HPs, which has been largely marginalized by philosophers and primatologists alike.

In the opening pages of her popular primer, Fundamentals of Comparative Cognition (2013, pp. 1-2), Shettleworth highlights two motivations for studying the animal mind. First, there are various "practical considerations" for "addressing issues in conservation and animal welfare," as well as for the construction of animal models for application in fields, such as neuroscience and genetics. Research motivated by these concerns is directly relevant to challenges discussed in the early sections of this chapter. Of special interest in the current discussion, however, is the second motivation that Shettleworth discusses: behavioral research motivated strictly by "sheer scientific curiosity." It is clear, for example, that the longest running and most popular issues regarding animal minds, tackled by philosophers and scientists alike, are chiefly addressed at questions of human uniqueness. As Shettleworth (2013, p. 2) claims, "What unifies this diverse field is the overarching question with which the modern study of comparative cognition began, how true is Darwin's (1871) assertion that humans' 'mental powers' are 'different in degree but not in kind' from those of other species?" The question as to whether Darwin was right to challenge this age-old, and still dominant, notion of human uniqueness is commonly thought justifiable for its own sake. Povinelli's work (2000; 2012) on chimpanzee "folk physics" offers a prime example of such research. Based on a series of experiments on captive chimpanzees at the New Iberia Research Center (NIRC), Povinelli argues that chimpanzees understand the physical world in a way that is fundamentally different from humans. It is worth noting, in line with the first part of this chapter, that the ecological validity of Povinelli's findings has been subject to great scrutiny. Within a year of publication, three scathing reviews of Povinelli's first book on the subject, by high-profile figures, appeared in comparative cognition (Hauser, 2001; Whiten, 2001; Allen, 2002). This second class of behavioral research (henceforth referred to as sheer curiosity-based behavioral research or $S C B B$ research) presents a unique ethical challenge that is not faced by other common forms of animal experimentation.

АСвв research can be defined as, experimental, or purely observational, behavioral research with no expected, or foreseeable, practical consequences. The motivations of the researchers are essential to this definition. Povinelli's experiments on the NIRC chimpanzees were not motivated by welfare concerns, nor were they motivated by future use in constructing animal models; rather, Povinelli and collaborators quite simply sought to gain knowledge as to whether chimpanzees understand the physical properties of objects in the same way that humans do (or, in many other of their experiments, whether chimpanzees possess a theory of mind). The majority of behavioral research 
on chimpanzees in comparative cognition is guided, first and foremost, by this basic desire to know for the sake of knowing (not to mention, of course, academic eminence, research grants, and the desire to publish). Further research and commentary is encouraged on this final point, as these overarching goals and features of academic culture are clearly relevant to the issue at stake.

When Shettleworth (2013, p. 2) claims that while "practical considerations motivate some research in animal cognition," an "equally important impetus for studying comparative cognition is sheer scientific curiosity," she is evoking the classic dichotomy between pure and applied science. In so doing, Shettleworth is aligning sсвв research with the former. Indeed, much of the animal minds literature tacitly operates under the banner of so-called, pure science, i.e., science without clear or direct practical implications. However, as is frequently argued in the philosophy of science, a strong case can be made that science is never entirely pure, insofar as the practice of doing science is never entirely value neutral. The costs and benefits of research at every step of the way-from motivating the research program to deciding upon the means to conduct it-are the result of tacit or explicit value judgments, including "a prior judgment to which moral considerations are pertinent" (Kitcher, 2001, p. 90; see also Gonzalez, 2013, for further commentary). With respect to Асвв research, for many experimenters who work in field, zoo, and research centers, traditional ethical criteria (such as the ${ }_{3} \mathrm{Rs}$ ) appear "puzzling and irrelevant" (Fedigan, 2010, p. 755); occasionally going "so far as to identify their projects as exempt from the entire oversight process" (Malone and Palmer, 2014, p. 25). While much of the current ethics literature on chimpanzee behavioral research (such as those cited above) provides strong reasons to reject this perspective (i.e., zoological institutions and field research clearly come with their own ethical concerns), in what follows we take a different critical approach by challenging the very basis for conducting some of this research in the first place. As these issues are broken down, scientific curiosity alone emerges as an extremely weak reason for breeding and confining animals.

\subsection{A Moral Challenge}

Practically all discussions of the ethics of animal experimentation (under any guise, context, motivation, or environment) involve some form of utilitarian calculus, i.e., "one that tries to weigh the beneficial consequences of experimentation with the costs associated with it" (Gruen, 2011, p. 118). The challenge that we pose to pure research facilities that breed and maintain animals solely to satisfy scientific curiosity is that such practices are incredibly difficult to justify on ethical grounds. There is even a crucial sense in which, given a utilitarian calculus, breeding and maintaining animals in captivity for the 
sole purpose of studying their behavior is more difficult to justify with reasoned arguments than invasive biomedical experiments. Invasive biomedical research clearly evokes more welfare concerns than behavioral research, but the welfare concerns in the former can be, and often are, argued away on the basis of anticipated practical benefit. sсвв research, on the other hand, may be legitimately said to evoke fewer welfare concerns. However, without any expected or foreseeable practical benefit to fall back on, convincing justification for breeding and maintaining chimpanzees in captivity_-rather than placing extant chimps in sanctuary-is by no means obvious. Therefore, despite the wealth of knowledge attained from captive studies, a large amount (perhaps even the majority) of behavioral research conducted on chimpanzees (past, present, and future) is far from easy to justify. There is clearly a very real challenge present here worthy of serious consideration.

Those who conduct SCBB research in zoological institutions, such as Frans de Waal at the Arnhem Zoo (e.g., de Waal, 1998) and Michael Tomasello at the Wolfgang Köhler Primate Research Center in collaboration with the Leipzig Zoo (e.g., Tomasello et al., 2007), are capable of offering additional justifications for captivity, e.g., the conservation efforts of their host institutions (see later discussion). However, it is very difficult to make a strong case that breeding and maintaining NHPs at pure research facilities, such as New Iberia Primate Research Center or the Yerkes National Primate Research Center, is morally justified. There are currently eight National Primate Research Centers in the Us, not including many other similar federally-funded institutions, such as the NIRC. Some of these institutions have conducted SСвB research on chimpanzees, in addition to more common biomedical studies. Both the Yerkes facility (Guha and Sullivan, 2015) and, more infamously, the New Iberia facility (Gruen, 2011, p. 116) have been subject to charges of ethics violations by the Humane Society of the United States, ultimately leading to the retirement of $220 \mathrm{New}$ Iberia chimpanzees to the Project Chimps sanctuary in 2016 (New Iberia Research Center, n.d.). Crucially, the line of argumentation presented here is not contingent upon these more egregious cases, but rather applies more broadly to challenging the ethical basis for keeping chimpanzees in captivity (even in "enriched" or "naturalistic" conditions) purely to satisfy scientific curiosity.

\subsection{A Moral Principle}

Let us proceed via demonstrative reasoning by agreeing to what we take to be an uncontroversial principle: interests motivated by the desire to satisfy intellectual curiosity (with no foreseeable or expected practical benefit) should not compromise or outweigh the welfare interests of others, because the former 
type of interests are comparably trivial relative to the latter. This principle is non-speciesist; it applies to research on humans as well as any sentient being capable of having interests. Importantly, it does not make all behavioral research unethical. For many animals raised in captivity, releasing them into the wild would clearly not be in their interests (Gruen, 2011). As such, for many animals already in social groups at zoological institutions, with conservation and/ or welfare-directed mission statements, this principle may readily promote their continued existence at the zoo, alongside other welfare interests of the NHP populations in question. For example, the Wolfgang Köhler Primate Research Center website claims that, "The breeding program at the zoo is framed within the global strategy of the European Endangered Species Program (EEP); and some research focuses on the husbandry and care of great apes in captivity". What is more, so long as the experiments themselves conducted in these environments can be convincingly argued to not violate the welfare of the test subjects, the principle is likewise not violated. The principle simply states that X's interests in bodily mobility, choice of social and sexual relations, general psychological well-being, and so forth, always outweigh Y's interests in satisfying their intellectual curiosity. It, therefore, follows that whenever X's interests and Y's interests are at odds, it is Y's obligation to explain why their interests to conduct Sсв в research are not trivial when compared to X's welfare interests; or, that Y's interests do not actually supersede any of X's welfare interests (as researchers in zoological institutions may claim). That said, the challenge that we have posed, based on this principle, is vital to future research programs because, if the above reasoning is sound, it seems to follow that none of the мсвв research conducted on the New Iberia chimpanzees, for example, was morally justified.

\subsection{Counter Argumentation}

Let us now consider several logical counter-arguments. To begin, some might take issue with the liberal use of the word practical and suggest, rightly, that while it is true that individual researchers may take themselves to be merely scratching an intellectual itch, the scientific enterprise as a collective effort almost always bears practical fruit, even from the most obscure research programs. If that is true, then the utilitarian calculus suggested here starts to look a lot more complicated. It requires the estimation of possible future utility of discoveries arising from research programs that, when undertaken, do not seem to have any practical value. As such, it is far from clear how such a utility calculation could be performed in any rigorous way.

Our response is as follows. When defining the parameters of sсвв research, we stressed the importance of researcher motivations because almost any 
pure research could be justified on the basis of ad hoc practical applications. Consider the theory of mind research. One foreseeable response to our conclusions is that work on theory of mind in chimpanzees does clearly have practical repercussions in the sense that this debate has been "central" to discourse on whether apes should be considered moral or legal persons (Lurz, 2011, p. 4). As such, a potential counter-argument might run along the following lines: as Malone and Palmer (2014, p. 34) note, "caregivers to orangutans at Auckland Zoo expressed the idea that zoo animals serve as 'martyrs' for their species, suggesting that individual sacrifice is justified for the sake of the 'greater good' of conservation. Similar ideas are often raised in discussions about the benefits of field research, alongside the notion that 'knowing more' makes such research inherently good". With respect to theory of mind research, those who breed and maintain chimpanzees at research facilities could argue that these individuals were, in some sense, "martyrs" for scientific knowledge that has, or may foreseeably have, practical applications regarding the welfare of their entire species.

This potential response is strongly unappealing for a number of reasons. First, there is no clear evidence that theory of mind research has led to progress for chimpanzees attaining legal personhood. Second, there is already sufficient evidence that chimpanzees have at least a "minimal" theory of mind (Call and Tomasello, 2008), which should satisfy any salient ethical concerns regarding the concept. Third, it is hypocritical for anyone who is motivated to defend theory of mind studies at research facilities, such as the NIRC, due to concern for the personhood status of chimpanzees, because any presumed or potential personhood status owed to those research subjects would be violated by their being bred and kept in such an environment. Fourth, the chimpanzees themselves quite clearly had no say in their presumed status as "martyrs". Fifth, as Gruen (2011, p. 129) notes, "Virtually every scientific article ends by claiming 'that more research is needed'. This is how research scientists make their living". Theory of mind research is no different; in fact, the theory of mind debate has long been subject to a well-known gridlock since decades worth of experimental and ethological research have failed to mitigate widespread skepticism under the guise of the so-called logical problem. Proponents of the logical problem claim that all approaches, past and present, that have been used to evaluate cognitive capacities, such as the presence of theory of mind in animals, "cannot provide evidence for this ability even in principle" (Halina, 2015, p. 474). In its basic form, the logical problem states that since all we can observe is an animal's behavior, it is difficult (if not impossible) to determine whether an animal is predicting the behavior of others by means of mental state attribution (e.g., of their underlying intentions and beliefs), or by means 
of associative or conditioned response-mechanisms. Since there is little reason to believe that the logical problem will be solved (Andrews, 2015), ad hoc justifications of Асвв research based on foreseeable ethical consequences of the theory of mind debate are clearly weak. Therefore, this same conclusion applies to any other research program commonly pursued at pure research centers for the sole purpose of scientific curiosity.

Another foreseeable counter argument would evoke the "naturalistic" or enriched conditions provided by research centers, such as Yerkes. It could be argued that, given these enriched conditions the ethics of captivity for primates in research centers deserves to be situated on a moral continuum with the apparent "naturalistic" conditions at zoological institutions, rather than in a separate category. We agree. Our response is that zoological institutions, such as Pongoland, are certainly not off the hook morally. We have excluded zoos from the heart of this discussion because the costs and benefits of their supposed conservation value is under scrutiny elsewhere (e.g., Alroy, 2015; Keulartz, 2015; Marino et al., 2010; Princée, 2016); but we readily grant that zoos and research centers exist on the same moral spectrum. With respect to this issue, we direct the reader to literature that explicitly considers the ethical weighing of zoological conservation efforts and welfare concerns brought upon by captivity (e.g., Davey, 2007; Gruen, 2011; Hosey, 2005, 2008; Keulartz, 2015) and grant that the challenges raised here apply to Nonetheless, in the absence of any clear benefits for the animals themselves, it is evident that SСвB research conducted at institutions, such as NIRC and Yerkes, cannot readily satisfy the self-evident moral principle that we have provided nor can any given utilitarian calculus that one may apply to justify this kind of research. Finally, it must be noted that the above is intended strictly as grounds for positing an important, yet critically underdiscussed, challenge for researchers to contend with-a moral dilemma that naturally arises when one attempts to justify $s c B B$ studies - rather than a direct indictment of any particular researchers or institutions.

\subsection{Concluding Remarks}

Those who engage in or otherwise defend sсвв research necessarily face a unique challenge not confronted by other forms of animal experimentation. All debates over animal experimentation evoke some sort of messy utilitarian or consequentialist calculus, wherein some foundation (firm or not) is provided to weigh the costs and benefits of breeding, maintaining, and experimenting on animals for research. However, when it comes to breeding primates (or any species, for that matter) purely for scientific curiosity at research centers, the calculus 
appears to come out the same every time: $\mathrm{S} \mathrm{в} \mathrm{в} \mathrm{research} \mathrm{is} \mathrm{unjustified} \mathrm{across} \mathrm{the}$ board. The extent to which this conclusion may also apply to similar research programs at zoos is far beyond the scope of this chapter but certainly one for further discussion. Also crucial for future discussion are the difficulties associated with justifying continued behavioral research by means of the conservation efforts of particular non-sanctuary research institutions, where such research is conducted (e.g., the Ape Cognition and Conservation Initiative in Iowa).

The following proposal is a corollary of the basic moral principle put forth and defended above; those who study animals in captivity must demonstrate either that:

1. The welfare interests of their research subjects are not compromised or outweighed in favor of interests derived solely from satisfying intellectual curiosity; and/or that

2. The dominant reasons for breeding and maintaining animals in captivity derive more from the welfare interests of the animals themselves than from purely intellectual interests.

The traditional act of breeding and maintaining non-human primates at research centers cannot readily satisfy these fair-minded conditions.

In terms of logistics, what exactly is being recommended here? We propose that the Us Fish and Wildlife Services (FWS) may have already, in part, paved the way. On September 14, 2015, the FwS officially granted endangered species status to chimpanzees living in the wild and in captivity. As a result, in order to use chimpanzees for biomedical research, one must apply for a special permit from the FWs. To date, only one permit has been applied for, which was granted in the interest of developing an Ebola vaccine for wild chimpanzees (Walsh et al., 2017). According to the FWs, however, behavioral research does not require such a permit. Such research would only require one, if it involves "actions that harm, stress, harass, or noticeably change the animal's behavior" (Grimm, 2015). If it can be convincingly argued via a combination of investigative journalism and welfare research on captive primates that these consequences do arise in captive chimpanzees, especially at pure research centers, a double standard could fairly be demonstrated here. Furthermore, "endangered species status" is largely irrelevant to the key issue at stake. One could readily expand this general proposal in the following way: All biomedical and behavioral research - not only that which involves NHPS, but all research involving captive canids, birds, bears, rodents, and others-should require such a permit. Research at zoological institutions would very likely be granted one, but it seems unlikely that future breeding and research programs conducted at more laboratory-oriented types of research institutions would. 


\section{References}

Abou-Ismail, U.A. and H.D. Mahboub (2011). The Effects of Enriching Laboratory Cages Using Various Physical Structures on Multiple Measures of Welfare in Singly-housed Rats. Laboratory Animals, 45(3), pp. 145-153.

Abramson, L.Y., M.E. Seligman and J.D. Teasdale (1978). Learned Helplessness in Humans: Critique and Reformulation. Journal of Abnormal Psychology, 87(1), p. 49 .

Allen, C. (2002). A Skeptic's Progress. Biology and Philosophy, 17, pp. 695-702.

Alroy, J. (2015). Limits to Captive Breeding of Mammals in Zoos. Conservation Biology, 29(3), pp. 926-931.

Andrews, K. (2015). The animal mind. New York: Routledge Press.

Arakawa, H., D.C. Blanchard, K. Arakawa, C. Dunlap and R.J. Blanchard (2008). Scent Marking Behavior as an Odorant Communication in Nice. Neuroscience and Biobehavioral Reviews, 32(7), pp. 1236-1248.

Archibald, K., R. Coleman, and T. Drake (2019). Replacing animal tests to improve safety for humans. In: K. Herrmann and K. Jayne, eds., Animal Experimentation: Working Towards a Paradigm Change, Vol. 22. Brill Human Animal Studies Series, pp. 417-442. Leiden: Brill.

Association for the Study of Animal Behaviour (2018). Guidelines for the Treatment of Animals in Behavioural Research and Teaching. Animal Behaviour, 135, pp. I-X.

Bailey, J. (2019). Genetic modification of animals: Scientific and ethical issues. In: K. Herrmann and K. Jayne, eds., Animal Experimentation: Working Towards a Paradigm Change, Vol. 22. Brill Human Animal Studies Series, pp. 443-479. Leiden: Brill.

Bailoo, J.D., T.S. Reichlin and H. Würbel (2014). Refinement of Experimental Design and Conduct in Laboratory Animal Research. Institute for Laboratory Animal Research Journal, 55(3), pp. 383-391.

Baker, K.C. and A.M. Dettmer (2016). The Well-being of Laboratory Non-human Primates. American Journal of Primatology, 79(1), pp. 1-5.

Baldwin, A.L., R.L. Primeau and W.E. Johnson (2006). Effect of Noise on the Morphology of the Intestinal Mucosa in Laboratory Rats. Journal of the American Association for Laboratory Animal Science, 45, pp. 74-82.

Bassett, L. and H.M. Buchanan-Smith (2007). Effects of Predictability on the Welfare of Captive Animals. Applied Animal Behaviour Science, 102, pp. 223-245.

Behavior on a Disk (n.d.). [online] Available at: https://norecopa.no/norina/behavior -on-a-disk [Accessed o5 May 2017].

Bekoff, M. (2013a). Are Pigs as Smart as Dogs and Does it Really Matter? Psychology Today: Animal Emotions. [online] Available at: https://www.psychologytoday.com/ blog/animal-emotions/201307/are-pigs-smart-dogs-and-does-it-really-matter [Accessed o6 May 2017]. 
Bekoff, M. (2013b). Are Pigs as Smart as Dogs, and Does It Really Matter? (Op-Ed). Live Science. [online] Available at: https://www.livescience.com/39717-are-pigs-as -smart-as-dogs.html [Accessed 18 November 2017].

Birkett, L.P. and N.E. Newton-Fisher (2011). How Abnormal Is the Behaviour of Captive, Zoo-living Chimpanzees? PLoS-One, 6(6), p. e20101.

Boesch, C. (2007). What Makes Us Human (Homo Sapiens)? The Challenge of Cognitive Cross-species Comparison. Journal of Comparative Psychology, 121(3), pp. 227-240.

Boesch, C. (2008). Taking Development and Ecology Seriously When Comparing Cognition: Reply to Tomasello and Call (2008). Journal of Comparative Psychology, $122(4)$, pp. 453-455.

Boesch, C. (2015). Similarities between chimpanzee and human culture. In: M.J. Gelfand, C.C. Ying-yi Hong, eds., Handbook of Advances in Culture and Psychology, Vol. 5. New York: Oxford University Press, pp. 1-37.

Boesch, C. and H. Boesch-Achermann (2000). The chimpanzees of the Taï Forest: Behavioural ecology and evolution. Oxford, Uk: Oxford University Press.

Bolhuis, J.J. and L.A. Giraldeau (2008). The study of animal behavior. In J.J. Bolhuis and L.A. Giraldeau, eds., The Behavior of Animals: Mechanism, Function and Evolution. Oxford, u K: Blackwell Publishing.

Braithwaite, V.A. and P. Boulcott (2007). Pain Perception, Aversion and Fear in Fish. Diseases of Aquatic Organisms, 75, pp. 131-138.

Brilot, B.O. and M. Bateson. (2012). Water Bathing Alters Threat Perception in Starlings. Biology Letters, 8, pp. 379-381.

Brosnan, S.F., L.M. Hopper, S. Richey, H.D. Freeman, C.F. Talbot, S. Gosling, S.P. Lambeth and S.J. Schapiro (2015). Personality Influences Responses to Inequity and Contrast in Chimpanzees. Animal Behaviour, 101, pp. 75-87.

Brown, E.K., V.L. Templer and R.R. Hampton (2017). An Assessment of Domaingeneral Metacognitive Responding in Rhesus Monkeys. Behavioural Processes, 135, pp. 132-144.

Burns, J.G., A.C. Price, J.D. Thomson, K.A. Hughes and F.H. Rodd (2016). Environmental and Genetic Effects on Exploratory Behavior of High-and low-predation Guppies (Poecilia Reticulate). Behavioral Ecology and Sociobiology, 7o(8), pp. 1187-1196.

Burwell, A.K. and A.L. Baldwin (2006). Do Audible and Ultrasonic Sounds of Intensities Common in Animal Facilities Affect the Autonomic Nervous System of Rodents? Journal of Applied Animal Welfare Science, 9, pp. 179-200.

Call, J. and M. Tomasello (2008). Does the Chimpanzee Have a Theory of Mind? 30 Years Later. Trends in Cognitive Sciences, 12(5), pp. 187-192.

Carvalho, C., D. Alves, A. Knight, and L. Vicente (2019). Is animal-based biomedical research being used in its original context? In: K. Herrmann and K. Jayne, eds., Animal Experimentation: Working Towards a Paradigm Change, Vol. 22. Brill Human Animal Studies Series, pp. 376-39o. Leiden: Brill. 
Chance, P. (1999). Thorndike's Puzzle Boxes and the Origins of the Experimental Analysis of Behavior. Journal of the Experimental Analysis of Behavior, 72(3), pp. 433-440.

Clayton, N. and N. Emery (2005). Corvid Cognition. Current Biology, 15(3), pp. R8o-R81.

Cohen, P.M., and L.R. Santos (2016). Capuchins (Cebus Apella) Fail to Show an Asymmetric Dominance Effect. Animal Cognition, pp. 1-15.

Comparative Intelligence and Cognition Laboratory (n.d.). [online] Available at: http://www.mjberan.com/ [Accessed 21 June 2017].

Cuthill, I.C. (2007). Ethical Regulation and Animal Science: Why Animal Behaviour Is Not So Special. Animal Behaviour, 74, pp. 15-22.

Darwin, C. (1871). The descent of man and selection in relation to sex. London, U K: John Murray.

Davey, G. (2007). Visitors' Effects on the Welfare of Animals in the Zoo: A Review. Journal of Applied Animal Welfare Science, 10(2), pp. 169-83.

Dettmer, A.M., S.S.K. Kaburu, K.L. Byers, A.M. Murphy, E. Soneson, L.J. Wooddell and S.J. Suomi (2016a). First-time Rhesus Monkey Mothers, and Mothers of Sons, Preferentially Engage in Face-to-face Interactions with Their Infants. American Journal of Primatology, 78, pp. 238-246.

Dettmer, A.M., L.J. Wooddell, K.L. Rosenberg, S.S. Kaburu, M.A. Novak, J.S. Meyer, and S.J. Suomi (2016b). Associations Between Early Life Experience, Chronic HPA Axis Activity, and Adult Social Rank in Rhesus Monkeys. Social Neuroscience, 1, pp. 92-101.

De Waal, F.B.M. (1998). Chimpanzee politics: Power and sex among apes. Baltimore, MD: Johns Hopkins University Press.

Dews, P.B. (1955). Studies on Behavior I. Differential Sensitivity to Pentobarbital of Pecking Performance in Pigeons Depending on the Schedule of Reward.Journal of Pharmacology and Experimental Therapeutics, 113(4), pp. 393-401.

Diamond, R.F., T.S. Stoinski, J.L. Mickelberg, B.M. Basile, R.P. Gazes, V.L. Templer, and R.R. Hampton (2016). Similar Stimulus Features Control Visual Classification in Orangutans and Rhesus Monkeys. Journal of the Experimental Analysis of Behavior, 105, pp. 100-110.

European Parliament (2010). Directive 2010/63/EU of the European Parliament and of the Council of 22 September 2010 on the Protection of Animals Used for Scientific Purposes. Official Journal of the European Communities, L276, pp. 33-79. [online] Availableat:http://eur-lex.europa.eu/legal-content/EN/TXT/?uri=CELEX\% 3A32010Loo63 [Accessed 12 August 2017].

Fedigan, L.M. (2010). Ethical Issues Faced by Field Primatologists: Asking the Relevant Questions. American Journal of Primatology, 72(9), pp. 754-771.

Feng, X., L. Wang, S. Yang, D. Qin, J. Wang, C. Li, L. Lv, Y Ma, and X. Hu (2011). Maternal Separation Produces Lasting Changes in Cortisol and Behavior in Rhesus Monkeys. Proceedings of the National Academy of Sciences, 108(34), pp. 14312-14317. 
Ferrari, P.F., A. Paukner, C. Ionica and S.J. Suomi (2009). Reciprocal Face-to-face Communication Between Rhesus Macaque Mothers and Their Newborn Infants. Current Biology, 19, pp. 1768-1772.

Gagliardo, A., P. Ioalè, M. Savini and M. Wild (2008). Navigational Abilities of Homing Pigeons Deprived of Olfactory or Trigeminally Mediated Magnetic Information When Young. Journal of Experimental Biology, 211(13), pp. 2046-2051.

Garner, J.P. (2005). Stereotypies and Other Abnormal Repetitive Behaviors: Potential Impact on Validity, Reliability, and Replicability of Scientific Outcomes. Institute for Laboratory Animal Research Journal, 46(2), pp. 106-117.

Garner, J.P. and G.J. Mason (2002). Evidence for a Relationship Between Cage Stereotypies and Behavioural Disinhibition in Laboratory Rodents. Behavioural Brain Research, 136(1), pp. 83-92.

Garner, J.P., G. Mason R. Smith (2003). Stereotypic Route-tracing in Experimentallycaged Songbirds Correlates with General Behavioural Disinhibition. Animal Behaviour, 66, pp. 711-727.

Gaskill, B.N. (2016). Stressed out! The Consequences of Environmentally Induced Stress on Mouse Models. Laboratory Animal Sciences Webinar. [online] Available at: https:// www.labroots.com/webinar/stressed-out-the-consequences-of-environmentally -induced-stress-on-mouse-models [Accessed 05 May 2017].

Gewin, V. (2011). Rats free each other from cages. Nature, News. [online] Available at: https://www.nature.com/news/rats-free-each-other-from-cages-1.9603 [Accessed 05 May 2017].

Gonzalez, W.J. (2013). Value ladenness and the value-free ideal in scientific research. In: C. Luetge, ed., Handbook of the Philosophical Foundations of Business Ethics. Netherlands: Springer, pp. 1503-1521.

Gouveia, K. and J.L. Hurst (2017). Optimising Reliability of Mouse Performance in Behavioural Testing: The Major Role of Non-aversive Handling. Nature, Scientific Reports, 7. [online] Available at: https://www.nature.com/articles/srep44999 [Accessed o6 May 2017].

Graham, J., T. Alloway and L. Krames (1994). Sniffy, the Virtual Rat: Simulated Operant Conditioning. Behavior Research Methods, Instruments, and Computers, 26(2), pp. 134-141. [online] Available at: http://www.wadsworth.com/psychology_d/ templates/student_resources/05346336o9_sniffy2/sniffy/main.htm [Accessed o6 May 2017].

Greek, R., and L.A. Kramer (2019). The scientific problems with using non-human animals to predict human response to drugs and disease. In: K. Herrmann and K. Jayne, eds., Animal Experimentation: Working Towards a Paradigm Change, Vol. 22. Brill Human Animal Studies Series, pp. 391-416. Leiden: Brill.

Greenwood, A.K., A.R. Wark, K. Yoshida and C.L. Peichel (2013). Genetic And Neural Modularity Underlie the Evolution of Schooling Behavior in Threespine Sticklebacks. Current Biology, 23(19), pp. 1884-1888. 
Greenwood, B.N., P.V. Strong and M. Fleshner (2010). Lesions of The Basolateral Amygdala Reverse the Long-lasting Interference with Shuttle Box Escape Produced by Uncontrollable Stress. Behavioural Brain Research, 211(1), pp. 71-76.

Grimm, D. (2015). Has us Biomedical Research on Chimpanzees Come to an End? Science. [online] http://www.sciencemag.org/news/2015/08/has-us-biomedical -research-chimpanzees-come-end [Accessed o6 May 2017].

Gruen, L. (2011). Ethics and animals. Cambridge, MA: Cambridge University Press.

Gruen, L., A. Fultz and J. Pretz (2013). Ethical Issues in African Great Ape Field Studies. Institute for Laboratory Animal Research Journal, 54(1), pp. 24-32.

Guha, A. and E. Sullivan (2015). Two Primates Die at Yerkes Due to Alleged Negligence. The Emory Wheel. [online] Available at: http://emorywheel.com/two-primates-die -at-yerkes-due-to-alleged-negligence/ [Accessed o6 May 2017].

Halina, M. (2015). There is No Special Problem of Mindreading in Non-human Animals. Philosophy of Science, 82, pp. 473-490.

Harlow, H.F. (1958). The Nature of Love. American Psychologist, 13(12), p. 673.

Harris, A.P., R.B. D'Eath and S.D. Healy (2010). A Cage Without a View Increases Stress and Impairs Cognitive Performance in Rats. Animal Welfare, 19(3), pp. 235-241.

Hassett, T.C. and R.R. Hampton (2017). Change in the Relative Contributions of Habit and Working Memory Facilitates Serial Reversal Learning Expertise in Rhesus Monkeys. Animal Cognition, 20, pp. 485-497.

Hauser, M.D. (2001). Elementary My Dear Chimpanzee, Science, 291, pp. 440-441.

Herrmann, K. (2019). Refinement on the way towards replacement: Are we doing what we can? In: K. Herrmann and K. Jayne, eds., Animal Experimentation: Working Towards a Paradigm Change, Vol. 22. Brill Human Animal Studies Series, pp.3-64. Leiden: Brill.

Hopper, L.M., S.P. Lambeth, S.J. Schapiro and A. Whiten (2015). The Importance of Witnessed Agency in Chimpanzee Social Learning of Tool Use. Behavioural Processes, 112, pp. 120-129.

Hosey, G.R. (2005). How Does the Zoo Environment Affect the Behaviour of Captive Primates? Applied Animal Behaviour Science, 9o(2), pp. 107-129.

Hosey, G.R. (2008). A Preliminary Model of Human-animal Relationships in the Zoo. Applied Animal Behaviour Science, 109(2-4), pp. 105-127.

Huston, M., D. DeAngelis and W. Post (1988). New Computer Models Unify Ecological Theory. BioScience, $38(10)$, pp. 682-691.

Jayne, K. (2014). Challenges Faced by Foraging Eastern Grey Squirrels, Sciurus Carolinensis: Competition, Pilferage and Predation Risks. PhD. University of Exeter: UK.

Jayne, K., G. Feenders and M. Bateson (2013). Effects of Developmental History on the Behavioural Responses of European Starlings (Sturnus Vulgaris) to Laboratory Husbandry. Animal Welfare, 22, pp. 67-78. 
Jayne, K., S.E.G. Lea and L.A. Leaver (2015). Behavioural Responses of Eastern Grey Squirrels, Sciurus Carolinensis, Tocues of Risk While Foraging. Behavioural Processes, 116, pp. 53-61.

Kano, F., C. Krupenye, S. Hirata and J. Call (2017). Eye Tracking Uncovered Great Apes' Ability to Anticipate That Other Individuals Will Act According to False Beliefs. Communicative and Integrative Biology, 10(2), p. e1299836.

Keulartz, J. (2015). Captivity for Conservation? Zoos at a Crossroads. Journal of Agricultural and Environmental Ethics, 28(2), pp. 335-351.

Killen, S.S., D.P. Croft, K. Salin and S.K. Darden (2015). Male sexually Coercive Behaviour Drives Increased Swimming Efficiency in Female Guppies. Functional Ecology, 30, pp. $576-583$.

Kitcher, P. (2001). Science, truth, and democracy. New York: Oxford University Press.

Klopfer, P.H. (1993). Ethology and noninvasive techniques. In: M.B. Kapis and S.C. Gad, eds., Non-Animal Techniques in Biomedical and Behavioural Research and Testing. Florida: Lewis Publishers.

Knight, J. (2001). Animal Data Jeopardized by Life Behind Bars. Nature, 412, p. 669.

Krachun, C. R. Lurz, J.L. Russell and W.D. Hopkins (2016). Smoke and Mirrors: Testing the Scope of Chimpanzees' Appearance-reality Understanding, Cognition, 150, pp. $53-67$.

Krupenye, C., F. Kano, S. Hirata, J. Call and M. Tomasello (2016). Great Apes Anticipate that Other Individuals Will Act According to False Beliefs. Science, 354(6308), pp. 110-114.

Laboratory of Comparative Primate Cognition (n.d.). [online] Available at: http:// www.psychology.emory.edu/lcpc/lab.html [Accessed 17 June 2017].

Leavens, D.A., K.A. Bard and W.D. Hopkins (2010). BIZARRE Chimpanzees Do Not Represent "The Chimpanzee". Behavioral and Brain Sciences, 33, pp. 100-101.

Leimgruber, K.L., A.G. Rosati and L.R. Santos (2016). Capuchin Monkeys Punish Those Who Have More. Evolution and Human Behavior, 37, pp. 236-244.

Lurz, R. (2011). Mindreading animals: The debate over what animals know about other minds. Cambridge, MA: Massachusetts Institute of Technology Press.

Lutz, C.K., K. Coleman, J.M. Worlein, R. Kroeker, M.T. Menard, K. Rosenberg, J.S. Meyer and M.A. Novak (2016). Factors Influencing Alopecia and Hair Cortisol in Rhesus Macaques (Macaca Mulatta). Journal of Medical Primatology, 45(4), pp. 180-188.

MacKinnon, K.C. and E.P. Riley (2010). Field Primatology of Today: Current Ethical Issues. American Journal of Primatology, 72(9), pp. 749-753.

Maier, S.F. and M.E. Seligman (2016). Learned Helplessness at Fifty: Insights from Neuroscience. Psychological Review, 123(4), p. 349.

Makowska, I.J. and D.M. Weary (2016). The Importance of Burrowing, Climbing and Standing Upright for Laboratory Rats. Royal Society Open Science, 3(6), pp. 160136. 
Malone, N. and A. Palmer (2014). Ethical issues within human-alloprimate interactive zones. In: G.L. Burns and M. Paterson, eds., Engaging with Animals. New South Wales: Sydney University Press.

Malone, N., A. Fuentes and F.J. White (2010). Ethics Commentary: Subjects of Knowledge and Control in Field Primatology. American Journal of Primatology, 72(9), pp. $779-784$.

Marino, L., S.O. Lilienfeld, R. Malamud, N. Nobis and R. Broglio (2010). Do Zoos and Aquariums Promote Attitude Change in Visitors? A Critical Evaluation of the American Zoo and Aquarium Study. Society \& Animals, 18(2), pp. 126-138.

Mason, G. and J. Rushen (2006). Stereotypic animal behaviour: Fundamentals and applications to welfare, 2nd ed. Oxfordshire: CAB International.

Massart, R., M. Suderman, N. Provencal, C. Yi, A.J. Bennett, S. Suomi and M. Szyf (2014). Hydroxymethylation and DNA Methylation Profiles in the Prefrontal Cortex of the Non-Human Primate Rhesus Macaque and the Impact of Maternal Deprivation on Hydroxymethylation. Neuroscience, 268, pp. 139-148.

Meier, C., S.E.G. Lea and I.P. McLaren (2016). A Stimulus-location Effect in Contingencygoverned, But Not Rule-based, Discrimination Learning. Journal of Experimental Psychology: Animal Learning and Cognition, 42(2), pp. 177-186.

Mwaffo, V., S. Butail and M. Porfiri (2017). In-silico Experiments of Zebrafish Behaviour: Modeling Swimming in Three Dimensions. Scientific Reports, 7, p. 39877.

Nelson, C.A., M. de Haa and K.M. Thomas (2006). Neuroscience of cognitive development: The role of experience and the developing brain. Hoboken, $\mathrm{NJ}$ : John Wiley \& Sons.

Neubert, F.X., R.B. Mars, J. Sallet and M.F. Rushworth (2015). Connectivity Reveals Relationship of Brain Areas for Reward-guided Learning and Decision Making in $\mathrm{Hu}-$ man and Monkey Frontal Cortex. Proceedings of the National Academy of Sciences, $112(20)$, pp. E2695-E2704.

New Iberia Research Center (n.d.). [online] Available at: https://nirc.louisiana.edu/ about-us/our-history [Accessed 6 January 2018].

Novak, M.A., A.F. Hamel, B.J. Kelly, A.M. Dettmer and J.S. Meyer (2013). Stress, the HPA Axis, and Non-human Primate Well-being: A Review. Applied Animal Behaviour Science, $143(2)$, pp. 135-149.

Pavlov, P.I. (1927). Conditioned Reflexes: An Investigation of the Physiological Activity of the Cerebral Cortex. Annals of Neurosciences, 17(3), pp. 136-141.

Pepperberg, I.M. (2017). Animal Language Studies: What Happened?. Psychonomic Bulletin \& Review, 24(1), pp.181-185.

Pippin, J.J., S.E. Cavanaugh, and F. Pistollato (2019). Animal research for Alzheimer Disease: failures of science and ethics. In: K. Herrmann and K. Jayne, eds., Animal Experimentation: Working Towards a Paradigm Change, Vol. 22. Brill Human Animal Studies Series, pp. 480-517. Leiden: Brill. 
Povinelli, D.J. (2012). World without weight: Perspectives on an alien mind. New York: Oxford University Press.

Povinelli, D.J., J.E. Reaux, L.A. Theall and S. Giambrone (2000). Folk physics for apes: The chimpanzee's theory of how the world works. New York: Oxford University Press.

Princée, F.P.G. (2016). Avoidance of selection. In: Exploring Studbooks for Wildlife Management and Conservation. Switzerland: Springer International Publishing, pp. 211-217.

Ram, R. (2019). Extrapolation of animal research data to humans: an analysis of the evidence. In: K. Herrmann and K. Jayne, eds., Animal Experimentation: Working Towards a Paradigm Change, Vol. 22. Brill Human Animal Studies Series, pp. 341-375. Leiden: Brill.

Reardon, S. (2016). A Mouse's House May Ruin Experiments. Nature, News, 530, p. 264. [online] Available at: https://www.nature.com/news/a-mouse-s-house-may-ruin -experiments-1.19335 [Accessed 6 January 2018].

Rosati, A.G. and L.R. Santos (2016). Spontaneous Metacognition in Rhesus Monkeys. Psychological Science, 27(9), pp. 1-11.

Schechtman, E., M.I. Noblejas, A.D. Mizrahi, O. Dauber and H. Bergman (2016). Pallidal Spiking Activity Reflects Learning Dynamics and Predicts Performance. Proceedings of the National Academy of Sciences, 113(41), pp. E6281-E6289.

Schmidt-Koenig, K. and H.T. Schlichte (1972). Homing in Pigeons with Improved Vision. Proceedings of the National Academy of Sciences, 69(9), pp. 2446-2447.

Shapiro, K.J. (1998). Animal models of human psychology: Critique of science, ethics and policy. Kirkland, Washington: Hogrefe \& Huber Publishers.

Shettleworth, S.J. (2013). Fundamentals of comparative cognition. New York: Oxford University Press.

Silk, J.B., S.F. Brosnan, J. Vonk, J. Henrich, D.J. Povinelli, A.S. Richardson and S.P. Lambeth (2005). Chimpanzees Are Indifferent to the Welfare of Unrelated Group Members. Nature, 437(7063), pp. 1357-1359.

Sliwa, J. and W.A. Freiwald (2017). A Dedicated Network for Social Interaction Processing in the Primate Brain. Science, 356(6339), pp. 745-749.

Taglialatela, J.P., J.L. Russell, S.M. Pope, T. Morton, S. Bogart, L.A. Reamer and W.D. Hopkins (2015). Multimodal Communication in Chimpanzees. American Journal of Primatology, 77, pp. 1143-1148.

Tecwyn, E.C. (2013). Physical Cognition in Great Apes: Planning and Object Compliance. PhD. University of Birmingham. U K.

Tecwyn, E.C., S.K.S. Thorpe and J. Chappell (2012). What Cognitive Strategies Do Orangutans (Pongo Pygmaeus) Use to Solve a Trial-unique puzzle-tube Task Incorporating Multiple Obstacles? Animal Cognition, 15(1), pp. 121-133.

Tomasello, M. and J. Call (1997). Primate cognition. Oxford, UK: Oxford University Press. 
Tomasello, M. and J. Call (2008). Assessing the Validity of Ape-human Comparisons: A Reply to Boesch, 2007. Journal of Comparative Psychology, 122(4), pp. $449-45^{2}$.

Tomasello, M., B. Hare, H. Lehmann and J. Call (2007). Reliance on Head Versus Eyes in the Gaze Following of Great Apes and Human Infants: The Cooperative Eye Hypothesis. Journal of Human Evolution, 52, pp. 314-320.

UK Home office (2012). Consolidated Animals (Scientific Procedures) Act 1986. Prepared from the Animals (Scientific Procedures) Act 1986 Amendment Regulations 2012. UK Government. [online] Available at: https://assets.publishing. service.gov.uk/government/uploads/system/uploads/attachment_data/file/619140/ ConsolidatedASPA1Jan2013.pdf [Accessed o6 May 2017].

UK Home Office (2017a). Annual Statistics of Scientific Procedures on Living Animals Great Britain 2016. [online] Available at: https://www.gov.uk/government/ uploads/system/uploads/attachment_data/file/627284/annual-statistics-scientific -procedures-living-animals-2016.pdf [Accessed o6 May 2017].

UK Home Office. (2017b). Animal Testing and Research: Non-technical Summaries. [online] Available at: https://www.gov.uk/guidance/research-and-testing-using -animals\#non-technical-summaries [Accessed o2 December 2017].

University College London (2017). Animal Research: Facts and Figures. [online] Available at: http://www.ucl.ac.uk/animal-research/facts-figures [Accessed 18 November 2017].

van Praag, H., G. Kempermann and F.H. Gage (2000). Neural Consequences of Environmental Enrichment. Nature Reviews Neuroscience, 1, pp. 191-198.

Waiblinger, E. and B. Koenig (2007). Housing and Husbandry Conditions Affect Stereotypic Behaviour in Laboratory Gerbils. Alternatives to Animal Experimentation, 24, pp. 67-69.

Walsh, P.D., D. Kurup, D.L. Hasselschwert, C. Wirblich, J.E. Goestzmann and M.J. Schnell (2017). The Final (Oral Ebola) Vaccine Trial on Captive Chimpanzees?. Scientific Reports, 7 , p. 43339.

Whiten, A. (2001). Tool tests challenge chimpanzees, Nature, 409, p. 133.

Wolfgang Köhler Primate Research Center (n.d.). [online] Available at: http://wkprc .eva.mpg.de/english/ [Accessed 17 June 2017].

Wooddell, L.J., S.K.K. Stefano, S.J. Suomi and A.M. Dettmer (2017). Elo-rating for Tracking Rank Fluctuations After Demographic Changes Involving Semi-free Ranging Rhesus Macaques (Macaca Mulatta). Journal of the American Association for Laboratory Animal Science, 56(3), pp. 1-9.

Würbel, H. and M. Stauffacher (1994). Standard-Haltung für Labormäuse - Probleme und Lösungsansätze. In Mason, G. and J. Rushen (2006). Stereotypic animal behaviour: Fundamentals and applications to welfare, and ed. Oxfordshire: CAB International. 
Würbel, H., M. Stauffacher, and D. von Holst (1996). Stereotypies in laboratory mice quantitative and qualitative description of the ontogeny of 'wiregnawing' and 'jumping' in ICR and ICR nu - mice. In Mason, G. and J. Rushen (2006). Stereotypic animal behaviour: Fundamentals and applications to welfare, and ed. Oxfordshire: CAB International.

Würbel, H. (2001). Ideal Homes? Housing Effects on Rodent Brain and Behaviour. Trends in Neuroscience, 24, pp. 207-211.

Würbel, H. (2007). Environmental Enrichment Does Not Disrupt Standardisation of Animal Experiments. Alternatives to Animal Experimentation, 24, pp. 70-73.

Yerkes National Primate Research Center (n.d.). Home. [online] Available at: http:// www.yerkes.emory.edu/index.html [Accessed 20 June 2017].

Zoo Atlanta (n.d.). Primate Research. [online] Available at: https://zooatlanta.org/ project/primate/ [Accessed 20 June 2017].

Zoratto, F., L. Manzari, L. Oddi, R. Pinxten, M. Eens, D. Santucci, E. Alleva and C. Carere (2014). Behavioural Response of European Starlings Exposed to Video Playback of Conspecific Flocks: Effect of Social Context and Predator Threat. Behavioural Processes, 103, pp. 269-277. 